Higher Education 6 (1977) 437-452

() Flsevier Scientific Publishing Company, Amsterdam - Printed in the Netherlands

\title{
PROBLEMS IN THE CONTEXT EVALUATION OF INDIVIDUALIZED COURSES
}

\author{
TJEERD PLOMP and ADRI VAN DER MEER \\ Department of Applied Mathematics, Section Educational \\ Research, Twente University of Technology, Enschede, \\ The Netherlands
}

\begin{abstract}
From 1970 to 1974 an Individualized Study System (ISS) for mathematics courses for first year engineering students was developed. Because of changes in the curriculum, new courses had to be developed from August 1974. The context evaluation of these new courses (ISS-calculus) consisted mainly of the evaluation of the mathematics courses developed during the preceding years. After a year the Department decided to suspend ISS as a teaching system for calculus partly because of dissatisfaction of the teachers with ISS-calculus.

This paper consists of two parts. Part one (sections 1,2) is a case study and summarizes the development of the system from 1970 to 1975 . It examines in detail the problems encountered in this development with special attention to the role of the executive teacher. The organization of an ISS-course and the planning decisions to be taken become more complex according to the number of executive teachers. In part two (sections 3,4 ) we provide a classification of ISS courses to illustrate the complexity of the system and we offer some general advice on the management of individualized study systems.
\end{abstract}

\section{Part One: Case Study}

\section{INTRODUCTION}

\subsection{Context evaluation}

The purpose of evaluation is to provide information for decision making. Different types of decision require different types of evaluation. Context evaluation serves planning decisions, i.e. it provides a basis for determining the objectives of a change in the educational system. Specifically, it defines the relevant environment, describes the desired and actual conditions pertaining to that environment, identifies unmet needs and unused opportunities and diagnoses the problems that prevent needs from being met and opportunities from being used. Diagnosis of problems provides an essential basis for developing objectives whose achievement results 
in program improvement (Stufflebeam et al., 1971).

In the construction of courses planning decisions often refer to changes of instructional methods and procedures (instrumental objectives of system change), while the intended course objectives remain unmodified. In this case, context evaluation refers to questions like what educational principles are underlying the structure of the course; what are the characteristics of the instructional procedures needed to reach the intended structure; what are the functions and the task of the teachers; in which way has a student to study in the course, what are the features of the management of the instructional system, etc.

\subsection{Development of the Individualized Study System}

From 1970 to 1974, the Department of Applied Mathematics and the Center for Educational Research and Development at the Twente University of Technology worked on the development (construction and evaluation) of a teaching system for freshman-mathematics (differential and integral calculus), which had to be suitable for large numbers of students. The system was called Individualized Study System (ISS) to indicate that instruction had to be adjusted as far as possible to the individual student. In the original specification, the ISS was required to meet two demands: (1) individualization of the educational process and (2) provision for systematic feedback on the learning process. Some implications of these demands are as follows:

a. Individualization: Within certain limits the student should be allowed to decide for himself when and how long he wants to work on given parts of the course. A substantial part of the subject matter must therefore be presented in the form of study materials suitable for independent use.

b. Systematic feedback: The feedback to the student on his achievements must be related to his progress through the subject matter and not tied to time. Division of the course into units or study tasks is necessary in order to make possible a selective feedback and to be able to correct the study process systematically. Between those tasks there will be a (partial) order.

The ISS-courses in mathematics were semester courses. The semester was divided into two courses of almost two months, called math 1 and math 2 . The successive versions of the system will be referred to as ISS 1 , ISS2, etc.

The first version, ISS1, was closely linked up with the traditional lecture system, of which the characteristics are: scheduled lectures and discussion-groups and examination at the end of the course. Individualization consisted chiefly in the amount of time a student could spend within each two-month period, on studying the given material. At the end of each such period, the student's performance was assessed by an examination identical with that taken by other students in the lecture system. 
The final versions of the system, ISS3 and ISS4, differ more radically from the traditional lecture system. There is no final examination anymore; the students' achievements are assessed by means of frequent tests related to the study tasks. Individualization is above all a matter of the students' own pace in working on the study tasks and following them with a test. This individualization in time and pace was achieved by assigning a central place to instructional aids, which can be used independently of the presence of a teacher, such as: (a) the text book, (b) a well-structured study guide to each study task (with information for optimal use of the course material and exercises) and (c) tv-lectures. Optional procedures are discussion groups and (in ISS4) lectures. They were used mainly to motivate students to keep to their study plan and to enable the group to discuss difficult problems.

The progress of the student in ISS3 and ISS4 is based upon the principle of mastery learning: a student is allowed to spend as much time on a study task as he needs to master the subject-matter of the task up to a given criterion. If there is a hierarchy of study tasks, then he is allowed to proceed to the next task, only when he has passed the test on the previous one in the hierarchy. It implies that a student who does not pass a test on a particular study task will receive written advice about his deficiencies. He can then take a new parallel test on the same study task. After having failed a test twice a student has to see his teacher or an assistant to discuss the causes of his failures before he can take a third parallel test. For a pass mark on the courses all the tests have to be passed.

The development of the individualized study system for freshman mathematics is described in Plomp (1974) and van der Klauw and Plomp (1974 a,b).

The main results of the evaluation of the final versions of the system (ISS3 and ISS4) may be summarized as follows:-

a. Student achievement: As a consequence of abolishing the examination in the ISS-courses, it was no longer possible to compare the ISS and the lecture system on a final examination. There was in the ISSystem a significantly higher percentage of passed students than in the lecture system.

b. Instructional and feedback procedures: The independent course material was accepted well by the students. They had little interest in the discussion groups and (in ISS4) the lectures. The feedback to the students functioned well in the final versions of ISS (van der Klauw and Plomp, 1974a).

c. Satisfaction of the students: In ISS3 as well as in ISS4 ca. $75 \%$ of the students appeared to have a strong preference for the ISSystem and ca. 15\% for the lecture system. The students thought they spent more hours but worked more efficiently in the ISSystem. The ISSystem required them to be more active and independent of a time-table, which they thought was an advantage. 
d. Satisfaction of the teachers: In ISS the task and the function of the teachers differ strongly from those in the lecture system. The teacher is no longer primarily a conveyor of information; this task is taken over by the course material. The main tasks in the teaching process are taking care of the discussion groups, tutoring individual students and providing feedback.

In ISS 3 the opinions of the six teachers on their teaching tasks were not unanimous. Four of them preferred the teaching tasks in the lecture system. But three of these teachers stated that this reason alone would not be a sufficient argument for preferring the lecture system to the ISSystem.

In the ISS 4 objections of teachers against ISS3 were removed by introducing a review task at the end of each course. In this review task, the following objectives are specified: (a) the students have to apply the subject matter from the preceding tasks in more complex problems than in other tasks, (b) the students get a view of the course as a whole, (c) by including some essay questions in the tests on the review task it is also possible to test how far a student is capable of formulating the logical steps in solving a mathematical problem.

\subsection{Implementation of ISS in new courses}

As a consequence of changes in the curriculum of Dutch secondary schools, the Council of the University decided in Spring 1974 to change the curriculum of the first year as of August 1974. The Council of the Department of Applied Mathematics, after considering the evaluation results from the development of the ISSystem, decided to offer all the first year courses in calculus for engineering students as ISS courses. These new courses - to be referred to as ISS-calculus - meant a scale enlargement of ISS in two ways: three successive trimester courses had to be developed for a group of ca. 245 students (compared with ISS4: a semester course for 115 students).

A group of three staff members was appointed as a preparatory committee for the construction of the courses, preparation of new course material, construction of tests for achievement and feedback etc. Six staff members (two of them were constructors too) were appointed to teach the courses. When at the end of the course the evaluation data were discussed in the department, it appeared that the dissatisfaction of the teachers with this new course had increased in such a way that the council of the department decided to suspend the ISS-courses, instead of transforming the points of criticism into improvements of the courses.

This result of extending ISS to new mathematics courses provides an opportunity to analyse where the context-evaluation of these new courses failed. The main sources for this context-evaluation were the evaluation data from the earlier ISS-courses in our department as well as elsewhere (see e.g. Pilot and Kramers-Pals (1973), Verreck (1973), Braak (1974), Gallup (1971), Hess (1971), Green (1971). Obviously, the context evaluation of 
ISS calculus should have been directed towards novel as well as towards familiar criteria. Central to these new points seems to be the position of the teachers in the ISS-courses: their task and function, their points of criticism, their satisfaction, etc. We take up these points below.

\section{DEVELOPMENT OF ISS3, ISS4 AND ISS-CALCULUS}

\subsection{ISS3}

2.1.1. Description of ISS3. In the development of the ISSystem, ISS3 was the first version based upon the principle of mastery learning. The independent course materials consisted of: a text-book, lectures on videotape (tv-lectures) and for each study task a well-structured study guide. Besides this, there was, once a week, a discussion group which enabled the teacher to lecture on some topics and to discuss problems, and which enabled the students to raise questions and to discuss them with their fellow-students. The performance assessment was by means of multiplechoice tests on the study-tasks and the progress was based upon the principle of mastery learning (see section 1.2).

Teaching tasks. The construction and evaluation of the several versions of ISS were carried out by the first author, assisted in some aspects by colleagues. The teaching tasks in ISS3 (130 students) were executed by six teachers. Their tasks were:

a. Taking care of discussion groups: two hours once a week, each teacher was responsible for a group of ca. 22 students.

b. Taking care of the performance assessment: there was no marking of examinations; the teachers assisted in determining the pass/fail score of the tests by judging test-items according to the method of Nedelsky (1954); test-taking was executed by student-assistants.

c. Tutoring individual students, especially those who failed a test twice. The teacher was free to choose another asseșsment procedure for such a student.

There were some meetings to prepare the six teachers for their changed tasks. During the course there were also some meetings to discuss the progress of the course. The teachers participated in the course voluntarily.

2.1.2. Evaluation of teaching tasks. The conclusions of the evaluation of ISS3 with respect to student achievement, the instructional and feedback procedures, satisfaction of the students and of the teachers have already been summarized in 1.2. Because of positive conclusions on the first three aspects we will restrict ourselves now to the evaluation of the task and function of the teacher and of the teaching tasks. 
Discussion groups. In ISS3 the discussion groups were judged rather negatively. $56 \%$ of the students who had attended discussion groups $(\mathrm{N}=$ 101) reported that the meetings had not paid off, whereas in ISS2 95\% thought the discussion groups profitable. (N.B. there was in ISS2 a final examination). The percentage of students attending the meetings was $20 \%$ to $40 \%$. Both students and teachers reported feeling uncertain about the purpose of the discussion groups, due to the introduction of the well-structured study guides (containing many hints the teachers used to give during the discussion groups) and the modification in the system of testing (no final examination; only tests on study tasks). Since there were differences in study rate the students came to the meetings with different levels of preparedness. Students did not find the discussions stimulating nor helpful for the planning of their own study. Some teachers reported that after the introduction of the study guide no real teaching was left to them. However, both teachers and students thought that group-meetings of some kind or other should be included in the ISSystem.

Performance assessment. From the six teachers in ISS3 four preferred a performance assessment by means of tests on study tasks to the final exam. This opinion was primarily based upon the comfort of the testing system for the student and the ease for the teacher (no marking of examinations) and upon the feedback function of the tests for the students. The teachers were asked to compare for the course math 1 and math 2 the level of the tests in ISS3 with that of the examinations in the lecture system. Only one of the teachers judged the math 1 examination as more difficult than the set of tests on the three study tasks. Three teachers judged both systems of performance assessment as equivalent, while the others had no opinion on this point.

Tutoring of individual students. During the semester 54 students were obliged to discuss with their teacher the problems they had had with passing some tests on study tasks. Forty-seven of them passed the test at their third attempt. Teachers as well as students stated that these consultations were very useful. Most of the teachers were of the opinion that this tutoring of students was a difficult part of their task.

2.1.3. General remarks. In 1.2 we noted that four (of the six) teachers preferred the teaching tasks in the lecture system to those in the ISS3, although for most of them this opinion was not decisive in choosing between the instructional systems. Three (of the six) teachers felt that the teaching tasks in ISS were more directed to the needs of the students than in the lecture system; only one of the teachers had an opposite view. All the teachers had the opinion that in ISS differences between students were taken 
into account more than in the lecture system. They had the same opinion about the functioning of the feedback procedures in ISS. Asked for their preference for an instructional system for the first year mathematics four (of the six) teachers chose ISS, one chose the lecture system, while one teacher argued for making both systems available in parallel.

The preference of the majority of teachers for the ISS did not mean they, as well as other teachers in the Department, agreed in all respects with the design and execution of ISS3. Some of them had criticisms to make of ISS3; these criticisms concentrated on three points:

a. Step-by-step testing system: in founding the final mark of the course on the results of tests on study tasks (as a consequence of abolishing the final examination) there was a fear that students would not have learned sufficient to be able to survey the subject matter of the whole course.

b. Multiple-choice questions: some teachers held the view that with this type of item a student was not forced to make all the necessary logical steps to solve the stated exercise. It was also pointed out that no attention is paid to the formulation of the solution of the exercise.

c. Mastery learning: to some teachers the heaviest objection against ISS in general was that ISS was not a sufficiently selective instructional system. In their opinion too many students were admitted to courses in the lecture system for which the ISS-course is the prerequisite.

The first two of these objections are not objections against the basic principles of ISS, but only objections against the way ISS3 was worked out. Both can be met by improvements. The objection against a basic principle of mastery learning is an objection against a basic principle of ISS. This objection can only be met by abolishing ISS-courses. But in ignoring this objection, by maintaining ISS-courses, a department takes the risk that some of the teachers will no longer be willing to participate in this type of teaching.

\subsection{ISS4}

2.2.1. Description of ISS4. In ISS4 the first point of criticism of the teachers (see 2.1.3) could be met by adding to the courses a review task. In studying this review task students get a view of the course as a whole. By including in the test on the review task some essay questions also the second point of criticism could be met. All other aspects of ISS4 are the same as ISS3.

Six teachers participated in the execution of ISS4; four of them had no experience with ISS. The teaching tasks were the same, except for one point: instead of assisting in determining the pass/fail scores of the tests, teachers had now to mark the essay questions in the review tests. As in ISS3, there were some meetings to inform the teachers about the course and to prepare them for their teaching tasks. 
2.2.2. Evaluation of ISS4. The most important conclusions of the rough evaluation of ISS4 are the same as in ISS3 (see sections 1.2 and 2.1.1). The teachers in ISS4 had the opinion that the introduction of the review task was indeed an improvement. However, their satisfaction with the teaching tasks in ISS was unaltered (see 2.1.3), as well as the reservations of some of the teachers about using the principle of mastery learning in university teaching.

\subsection{ISS-calculus}

2.3.1. Description of ISS-calculus. From August 1974 a new curriculum for the first year of study for engineering students had to be introduced. As a consequence of changes in the secondary school, it was necessary to develop new courses. The department of applied mathematics decided on the basis of evaluation of ISS3 and ISS4 that the new calculus courses should be presented as ISS-courses (ISS-calculus), in spite of the opinion of the teachers.

The Engineering Departments asked for the following points to be taken into account during the preparation and evaluation of the courses:

a. the effect of the testing system; frequent tests during the course, may divert the attention of the students from other compulsory and concurrent (lecture-) courses;

b. notwithstanding the step-by-step testing system the courses should be at a sufficient level;

c. in the tests attention must be paid to essay questions;

d. if possible, to research into whether the ISS-courses are as good as courses in the lecture system (with an examination).

From these points (which partially agree with the objections from mathematics teachers against ISS3, see section 2.1.3) and from an inventory of objections against ISS within the University (Donders, 1974) it was concluded that during the preparation of the new courses ISS-calculus a large number of questions and doubts of staff members had to be taken into account.

Other problems for the preparatory committee were:

a. Because of the late moment of decision (April 1974) little time was available for preparing new study materials and new tests.

b. The basic text chosen for the new calculus courses was not written for an ISS-course, but for a lecture course. That meant that in the study guides much attention had to be paid to explanation of this basic text.

c. One had to try to remove some of the objections of the teachers against the teaching-tasks (see section 2.1.1).

d. Due to changes in subject matter, one could no longer make use of the tv-lectures as an alternative to the written study material.

Three trimester courses were designed for the ca. 240 freshmen 
engineering students. Each course consists of six study tasks; the sixth task is a review task. The following instructional procedures were available:

a. Basic text with exercises.

b. Study guides for each task, containing objectives, explanation of and supplement to the basic text, study questions with some examples of multiple choice test items.

c. Group sessions: two weekly sessions (each of four hours) were planned for:

1. lectures: two hours weekly (as substitute for the tv-lectures);

2. discussion groups (see section 2.1.1);

3. study facilities: to give students the opportunity to study in the lecture hall where the teacher is available for help.

The performance assessment was, as in ISS3 and ISS4, by means of tests on the study tasks. The tests were mainly composed of multiple-choice items (sometimes an essay question was inserted) whereas for the review task half of the test consisted of essay questions. The progress in the course was based upon the principle of mastery learning (as in ISS3 and 4, see section 1.2).

Teaching tasks in ISS-calculus. The teachers had to carry out the following tasks:

a. Lecturing (two hours a week);

b. Taking care of the discussion groups;

c. Taking care of the study facilities;

d. Tutoring individual students;

e. Marking of the essay questions in the review tests.

Supervision of test-taking and the marking of the other tests were carried out by student-assistants. To assist them in the tutoring of students the teachers received a weekly survey of the tests made by the students. The ISS-calculus courses were executed by six teachers; two of them were members of the preparatory committee. Three teachers participated for the first time in ISS-courses.

Division of the teaching tasks. In the preceding courses a teacher took care of all the teaching tasks for a small group of ca. 22 students. Because of the lack of interest of the students for the discussion groups it did not seem worthwhile to choose the same set-up. Since teachers prefer to execute their teaching tasks with a fixed group of students the other extreme was not desirable either, viz. to assign to every teacher some of the tasks (e.g. one teacher for the lectures, two or three for tutoring, all teachers for marking tests, etc.). By opting for a set-up in which two teachers for all tasks were assigned to a group of ca. 80 students, the wishes of the teachers were taken into account and, besides that, an efficient spending of time for the teachers 
seemed to be possible. In two meetings the set-up of the courses was discussed with the teachers. During the course there were regular meetings to discuss progress of the courses.

2.3.2. Evaluation of ISS-calculus. The (process and product) evaluation was focused on the following topics: (a) study results, (b) amount of time spent by students, (c) idem for teachers, (d) quality of course materials and (e) satisfaction of the students (van der Meer, 1975). No attention was explicitly paid to the satisfaction of the teachers. We expected that their opinion about the course - especially about their own functioning - would become obvious in the regular meetings of the teachers. Besides, the design of the evaluation had been discussed with the teachers.

The conclusions from the evaluation with respect to the points $a, b, c$ and e were satisfactory. An average of ca. $80 \%$ of the students passed the various ISS-calculus courses. The mean time of the students for the courses was below the standard set by the University. Some students (ca. 20\%) had to spend longer and this was at the expense of other first year courses. The time the teachers spent on their teaching tasks was lower than in the lecture system but the arrangement of the testing system took much studentassistant time. The satisfaction of the students with the courses was high. Separate attention has to be paid to some aspects of the evaluation:

Course material: The teachers thought the study guides too extensive, often too detailed and sometimes erroneous. The students approved the course material as a whole, although they had some reservations about the basic text.

Tests: Teachers' opinions about the level of tests differed. These differences can be reduced to disagreements about the objectives of the courses: in the lecture system objectives are mostly implicit, in ISS-courses they are explicit.

Teaching tasks: Each pair of teachers worked in their own way. In all the groups, students' interest diminished after an initial good start; the same held to a large extent for the study facilities. Because there is less to lecture in ISS, most of the teachers (especially those who had not participated in the preparation of the courses) felt themselves more administrator than teacher. It was also difficult for the teachers to fit their teaching activities to the variations in study tempo of the students. As in the preceding ISS mathematics course we have to conclude that, in our situation, teachers who contribute to the ISS-courses only by means of teaching tasks, draw from these tasks less satisfaction than from the teaching tasks in the lecture system.

The results of the evaluation were discussed in the council of the department. It was obvious that the first version of ISS-calculus would have to be improved. It was noted, however, that not enough teachers were 
willing to participate in the $1975 / 76$ courses. Teacher satisfaction (which was not explicitly a topic of evaluation) therefore became a major point in the discussion and failure to resolve this point led to the decision to stop the ISS-courses.

\subsection{Conclusion}

In the context evaluation of ISS-courses, further research is needed to discover which problems can occur, in order to ensure that when new courses are introduced they have an optimal chance of success. Hitherto evaluation has been directed mainly at problems concerned with the construction and the management of the courses. From our experience the organization of a course becomes more complex as the number of teachers involved in the execution of the course increases. In part two of this article we classify ISS-courses according to complexity of organization.

\section{Part Two: Analysis}

\section{CLASSIFICATION OF ISS-COURSES ACCORDING TO THEIR COMPLEXITY}

\subsection{Introduction}

It is useful to discriminate between preparatory and executive tasks in an ISS-course. Preparatory tasks are:

a. determination of preliminaries and objectives;

b. choice of a convenient reference text, arrangement of the contents in study tasks, determination of the hierarchy in the study tasks;

c. design of the procedures for teaching, feedback and assessment;

d. preparation of the study materials viz. a reference text if necessary, study guides and other materials such as video tapes, etc.

e. operationalization of the objectives, construction of the tests, fixing the fail/pass scores;

f. preparation of the organization, such as fixing the testing dates, halls, time tables, consulting hours, etc.

Executive tasks are:

g. giving lectures and providing for question-periods;

h. giving individual help to students with problems;

i. administration of tests and registration of student progress; wrong;

j. management of the course, adjustment when things threaten to go

k. gathering and ordering of comments on tests, study-text and other materials;

1. formulation of proposals for improvement in the next version, starting from experiences with the present one. 
The organization of the course will become more complex as the number of teachers grows. In the following classification the most important topics in context-evaluation will be mentioned, partly based on our own experiences, partly on Green (1972) and Gallup (1971).

\subsection{Type I: one-man courses}

Characteristics: construction and execution of the course are in the hands of the same person. He may be advised by colleagues in the preparation and be assisted by skilled students in the execution.

Topics in the context evaluation

1. Time: there must be enough time for the construction. Even a small course requires several months of full-time preparation. It is necessary to set the preliminaries and objectives at an early stage.

2. Choosing undergraduate assistants: selection, instruction and coaching of the assistants is an often underestimated problem. In the calculus-course in Twente work with these students began early in the preparatory stage.

3. Acceptance by the faculty: the fact that more students than expected pass in an ISS-course turns out to be difficult for colleagues to accept. When the course replaces a classical course in which many students fail, the rumour that the standards are lowered will spread quickly.

4. Evaluation activities: during the course there must be enough time available for activities connected with process- and product-evaluation of the course.

5. Procrastination problem: Students tend to put off taking the tests. A solution to this problem must be found before the start of the course so that the measures resulting from this can be announced in time. Hess (1971) gives a number of strategies: use of a cumulative record per student, use of an early one-shot time contingency in the course, contacting students falling more than one week behind the rate of progress, etc.

\subsection{Type II: Team courses}

Characteristics: the course is constructed and executed by the same group of teachers.

Topics in the context-evaluation: the problems which occur in Type I will exist here also. Because of the more complicated pattern of cooperation a number of new problems will arise:

6. Consensus: all members of the group must completely agree with the basic principles of the course.

7. Distribution of construction tasks: in the construction phase of the course the tasks have to be distributed in an appropriate way and properly coordinated. 
8. Distribution of executive tasks: at this stage, the distribution of tasks is often more difficult. Some tasks are more in demand than others. There is a tendency to split the course into several one-man courses by assigning each member of the team to a fixed group of students. This decreases efficiency because many of the tasks will be duplicated. On the other hand, in special cases the loss of efficiency will balance the gain in teacher satisfaction.

9. Public relations: the distribution of tasks, mentioned in (8) must be clear to others. One person must especially be assigned to take care of external relations. In addition, students must know who can help them with which problems.

\subsection{Type III: Courses with guests}

Characteristics: as for type I or II but the work is extended by using additional teachers who supply incidental contributions, for instance illustrative lectures (enrichment sessions). They do not, however, bear final responsibility for the course.

Topics in the context evaluation: all topics of the types I and II occur here too. In addition:

10. For the guests: they must be aware of and accept the function of their contribution and be able to supply it.

11. For the course authorities: the contributions must be placed at the right time in the course and announced beforehand.

\subsection{Type IV: Executive team different from preparatory committee}

Characteristics: the team that constructed the course is extended by including a group of teachers who share with it the final responsibility for the results. The courses dealt with in the sections 1 and 2 belong to this type.

Topics in the context evaluation: in this type too the topics 1 to 9 and possibly 10 and 11 are relevant. The points 2 : coaching assistants, 4: evaluation activities and 9: public relations become more complex because more people are involved. Number $8:$ distribution of executive tasks, becomes so much more complex that for this type it has to be elaborated still further. Special attention has to be paid to relationships between the course constructors and the team that teaches the course (van der Meer and Plomp, 1977).

\subsection{Satisfaction of teachers}

Most of the problems mentioned can be summarized in terms of satisfaction of teachers: nearly all difficulties arise when the danger of dissatisfaction is underestimated. We agree with Vroon (1975) who, writing about Dutch universities, states that intensive concern with teaching problems is inhibited rather than stimulated. Scientific achievements are 
rated higher than didactical skills; one does not make a name by improving one's teaching but by writing a highly specialized dissertation and by adding to one's list of scientific publications. Add to this the short life of up-to-date professional knowledge which hardly justifies a staff member being preoccupied with full-time teaching for several months, the lack of financial support for innovations in teaching and, last but not least, the credibility gap between teachers and professional educational experts, and it can be seen why educational developments are resisted. But emotion, seldom explicitly expressed, also plays a part. Intensive interaction with students obviously asks for skills other than the verbal-rhetorical. The teacher who is used to conveying his knowledge in an instructional situation that guarantees minimal participation of the students, for instance a traditional lecture, finds new modes of working threatening.

\section{CONCLUSIONS AND DISCUSSION}

The introduction of a new instructional system involves problems which cannot be completely foreseen. The purpose of this paper is to clarify and to analyze problems in the context evaluation of the individualized study system with special attention to the role of the executive teacher. Some general conclusions and points of discussion can be drawn from the analysis of the problems in the context evaluation mentioned in section 3. Most of them can be used in or translated to the context evaluation of any other new instructional system.

\subsection{Rationalization of emotional resistance}

The history of the development of the ISS in our university gives an indication for the conjecture that the main problem in courses type IV, the (dis)satisfaction of the "new teachers," is never formulated by them as an emotional problem. Teachers try to translate their resistance against the system into rational objections. Efforts to remove the grounds of these objections by changing the system do not remove the emotional resistance but evoke new and sometimes even the same rationalizations and thus reinforce the resistance. However, one must also consider the arguments as they are formulated, and not too readily consider them as rationalizations only.

An example of an argument that may be considered both as rational and as a rationalization is that of the level of the course (see sections 2.1.3 and 3.2.1). On the one side the argument that the level is lowered with respect to that of a lecture course is easy to reject: usually there is no empirical evidence for such an argument. But on the other hand by the detailed specification in an ISS-course there is a chance of throwing away some objectives which are not so easy to operationalize, e.g. skills to transfer knowledge. 


\subsection{Satisfaction of students and teachers}

It is obvious that teaching will fail if the teachers completely reject the system. Usually the situation is not so extreme. In most cases a certain dissatisfaction of the teachers makes the question of maintaining or altering the instructional set-up of the course a matter of current interest.

On the other hand the satisfaction of students is important too, and it is well known that usually this satisfaction is higher in an individualized course than in a traditional lecture system.

The question is, what has to be decisive: satisfaction of students or satisfaction of teachers? Both must be above a certain minimum but it is an open question how to operationalize this minimum. This question is not only important for individualized study systems but for instructional systems in general.

\section{References}

Braak, L. H. (1974). Geindividualiseerde onderwijssystemen: konstruktie en besturing. Eindhoven (Neth.): dissertation.

Donders, J. M. (1974). Invoering ISSystemen in het curriculum. Enschede: Technische Hogeschool Twente, CDO.

Gallup, H.F. (1971). "Problems in the implementation of a course in personalized instruction." Paper presented at "Personalized Instruction: a symposium in honor of Fred Keller", American Psychological Association Meeting. Also in Sherman, J. G., ed., (1974).

Green, B. A. (1971). "Physics teaching by the Keller-plan at M.I.T.," Am. J. Phys. 39: 764-775. Also in Sherman, J. G., ed., (1974).

Green, B. A. (1972). "Fifteen reasons not to use the Keller Plan," presented at the Keller Method Workshop Conference at Rice University, Houston, Texas. Also in J. G. Sherman, ed., (1974).

Hess, J. H. (1971). “Keller-plan instruction: implementation problems." Paper presented at Keller Plan Conference at M.I.T., Cambridge (Mass.). Also in Sherman, J. G., ed., (1974).

Klauw, C. F. van der and Plomp, Tj. (1974a). "The construction and evaluation of a feedback system," in Verreck, W. A., ed., Methodological Problems in Research and Development in Higher Education, pp. 237-258. Amsterdam: Swets \& Zeitlinger.

Klauw, C. F. van der and Plomp, Tj. (1974 b). "Individualized Study Systems in Theory and Practice," Higher Education 3(2), 213-230.

Meer, A. van der (1975). Rapport van de begeleidingskommissie evaluatie ISS. Enschede (Neth.): T. H. Twente, Dept. of Applied Mathematics.

Meer, A. van der and Plomp, Tj. (1977). "Kontekstevaluatie van Individuele Studie Systemen," Pedagogische Studiën 54 (July/August).

Nedelsky, L. (1954). "Absolute grading standards for objective tests," Educ. Psychol. Meas. 14.

Pilot, A. and Kramers-Pals, H. (1973). "De constructie van een individueel studiesysteem materiaalkunde voor eerstejaars aan de T.H. Twente," in van Woerden, W. M., et al., ed., Onderwijs in de maak. Utrecht: Spectrum, Aula 508. 
Plomp, Tj. (1974). De ontwikkeling van een Individueel Studie Systeem. Groningen (Neth.): Tjeenk Willink.

Sherman, J. G., ed. (1974). Personalized System of Instruction: 41 Germinal Papers. Menlo Park (Calif.): W. A. Benjamin.

Stufflebeam, D. J., et al. (1971). Educational evaluation and decision making. Itasca (IIl.): F. E. Peacock Publ.

Verreck, W. A. (1973). Individualisering in het wetenschappelijk technisch onderwijs. Eindhoven: dissertation.

Vroon, A. G. (1975). "Onderwijsverbetering, een zaak van onderwijskundigen?" Universiteit en Hogeschool 22(2), 92-100. 